STRUCTURAL SCIENCE CRYSTAL ENGINEERING MATERIALS

ISSN 2052-5206

\title{
Highlights in Mineralogical Crystallography. Edited by Thomas Armbruster and Rosa Micaela Danisi. De Gruyter, 2015. Hardcover, Pp. XII+201. Price EUR 99.945, USD 140, GBP 74.99. ISBN 9783110417104.
}

\author{
Koichi Momma* \\ National Museum of Nature and Science, 4-1-1 Amakubo, Tsukuba, Ibaraki 305-0005, Japan. *Correspondence e-mail: \\ k-momma@kahaku.go.jp
}

Keywords: book review; mineralogical crystallography.

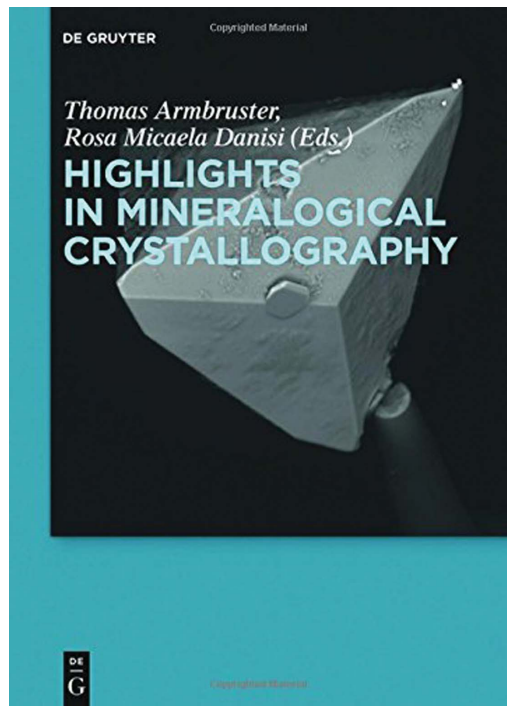

C 2016 International Union of Crystallography
While the structural study of biomaterials recently seems to be attracting increasing attention in crystallographic effort, mineralogy formed a foundation for modern crystallography and there are still many open important questions in this field. Highlights in Mineralogical Crystallography was written to describe some of these hot topics. To broaden the field of vision of the book, it was written by a young generation of leading scientists.

Chapter 1 introduces the power of mineralogical databases constructed by the RRUFF project. The aim of the RRUFF project is to develop a database covering a variety of experimental data such as Raman spectroscopy, X-ray powder diffraction data, and chemical compositions etc. of various minerals. With the help of the International Mineralogical Association (IMA) and its nomenclature commission, an online database on IMA-approved minerals is also developed and maintained. The authors describe a brief history of the project, procedures of data acquisitions, a list of features of the database, and some topics related to the construction of the database.

Chapter 2 discusses the structural complexity of minerals and mineral parageneses from a viewpoint of information theory. Various indices for expression of parsimony and complexity of crystal structures are explained, and some of these indices are used to understand chemical reactions in the real world such as the ease of crystallization of polymorphs and parageneses of minerals. It is argued that the general trend of mineral evolution corresponds to an increase in diversity and complexity of mineral structures.

Chapter 3 considers mineral surfaces as the surface structures of minerals are gaining increasing attention for a better understanding of the chemical reactions of minerals. Theoretical background on the surface structures of crystals and a variety of simulation methods of surfaces is explained in the early part of the chapter. The latter half of the chapter describes case studies on surface structures of five minerals in detail.

Chapter 4 focuses on natural quasicrystals. The discovery of quasicrystals in 1984 brought a revolution in crystallography, and the discovery of natural quasicrystals in 2009 was also a revolution in mineralogy. The first natural quasicrystal mineral, icosahedrite $\left(\mathrm{Al}_{63} \mathrm{Cu}_{24} \mathrm{Fe}_{13}\right)$, was discovered in a museum collection labeled as khatyrkite $(\mathrm{Cu}, \mathrm{Zn}) \mathrm{Al}_{2}$, collected in Kamchatka peninsula, Russia. The discovery story, a variety of experimental data, the origin of icosahedrite, and the discovery of new samples and new quasicrystal mineral decagonite are described.

Chapter 5 casts a spotlight on ringwoodite, a high-pressure phase of $\mathrm{Mg}_{2} \mathrm{SiO}_{4}$. It is one of the major constituent minerals in the mantle transition zone. Influences of $\mathrm{Mg} / \mathrm{Fe}$ substitution and incorporation of water in its crystal structure are explained to have a great impact on its stability field and thermoelastic properties. Implications of its thermoelastic properties for earth science and significance of ringwoodite as the Earth's water storage are also discussed.

Chapter 6 covers investigation of bio-related minerals by electron-diffraction tomography. Automated diffraction tomography (ADT) is a relatively new technique in transmission electron microscopy that enables ab initio determination of lattice parameters and crystal structures. Compared with other electron diffraction methods, it has a number of advantages allowing more complete, less dynamical and faster diffraction data 
collection. The procedures of data collection are explained and three examples of structure determination of bio-related nanocrystalline minerals are described.

Chapter 7 picks up mayenite $\mathrm{Ca}_{12} \mathrm{Al}_{14} \mathrm{O}_{32}\left[X^{2-}\right]$ as an example of the strong link between mineralogy and material science. Mayenite-group crystals, the first thermally and chemically stable electrides, are a rare class of compound in which electrons behave as anions. The crystal structure of mayenite consists of an interconnected $\mathrm{AlO}_{4}$ tetrahedral framework supported by $\mathrm{Ca}^{2+}$ cations, and contains extra framework anions. Because of its low-density microporous framework structure, it has anion-exchange capacity and ion conductivity. Such characteristics of mayenite allow its use as a catalyst, transparent conducting oxide or crystalline electride.

In summary, this book picks up some of the latest hot topics of mineralogical crystallography rather than covering general principles. I would recommend this publication to both mineralogists and crystallographers. It provides us with some idea of the types of challenges in modern mineralogical crystallography and how they are linked with other realms of science. 